\title{
Role of National Culture on the Use of e-Government Services in Sri Lanka
}

\section{Ranaweera HMBP*}

School of Public Administration, Huazhong University of Science and Technology, Wuhan, PR China

Department of Business Management, Faculty of Management Studies, Rajarata University of Sri Lanka, Mihintale, Sri Lanka

\begin{abstract}
The role of national culture on the use of e-government services in Sri Lanka is explored in this study employing the Technology Acceptance Model (TAM) as the theoretical framework. The national culture was added to TAM as an external variable and extended model is tested via a survey of 898 Sri Lankan e-government service users. Structural Equation Modeling (SEM) was utilized as analysis technique and results of the structural analysis divulge that national culture makes influences positively on the use of e-government services. Besides, perceived usefulness and perceived ease of use of government websites also are influenced by national culture. Collectivism, Long term orientation and Uncertainty avoidance were the key contributing dimensions of culture in the Sri Lankan context. Nevertheless, these results suggest that TAM can be further extended by examining the nature of the e-government use and the national culture. Cultural traits should be considered in understanding the use of e-government services in Sri Lanka and the outcomes of this paper would be intrinsic worth for policy makers to pay more attention on national culture when investments are made to e-government initiatives.
\end{abstract}

Keywords: e-Government; Technology acceptance model; National culture; Structural equation modeling; Sri Lanka

\section{Introduction}

E-government means utilizing ICT facilities available in internet and web based technologies to offer government services to general public as well as to improve the government services [1-3]. To proper function the e-government initiatives, there should be IT savvy culture within government organizations as well as among the general public. Most of the governments around the world still are confronting the issues with regard to acceptance, adoption and use of e-government services regardless of the possible benefits of vast e-government projects [4-6] because issues are multi-dimensional in nature. The core issues of the e-government domain are from social side (user's demand) not from technical side [7]. Even though, some issues have been examined much more, still there are some other aspects which are yet to be explored [8]. These issues must be addressed not only from technical perspective but also social and cultural perspective [5]. The importance of culture for technology adoption and use in particular for the e-government services has been pointed out in prior studies [916]. Culture represents how social groups interact with each other and how distinguishes societies, institutes, professions or even countries. At the same time, culture explains how people in social groups interact with new technological innovations. However, it has not been paid much more attention regarding this particular factor and less explored $[9,17,18]$ especially in developing countries. It seems that researches which have been addressed the cultural influences on the use of e-government services are rare in the Asian region in general and in particular Sri Lanka.

Different culture represents different behaviors and act differently on technological changes. Individual's expectations or hopes are influenced by cultural differences. Thus, it is important to identify the role of culture in the technology acceptance and adoption studies as multi-cultural characteristics of users in a country may make considerable influences for new technological innovations like e-government. A better understanding of cultural impact in this e-government context will be helpful for policy makers in the area of e-government, system developers to make development in a better way and cost effective manner to serve for culturally different people. These improvements will cause to attract and retain users for continuous use. Given the aforementioned evidences, the scope of this paper is to find an answer to the following research question.

\section{Research question}

Does national culture make impact on the use of e-government services in Sri Lanka?

The rest of the paper is compiled as follows. The brief explanation on the background of the study and literature evidences are presented in section two, followed by the theoretical framework and the research model in section three. Research methodology and analysis is discussed in section four while section five is devoted to present the research results and discussion. Conclusion of the research, limitations and future research direction are brought in section six and seven.

\section{Background and Literature Evidences}

Apart from technical and management related factors, human factors which are related to cultural and social elements in developing countries are very much important for user behavioral decisions on the adoption and use of e-government services. Negligence of cultural traits will be acted as hindrances for adoption and use of new technological systems [10]. Hence, non-technological factors are very much important. However, few studies have been explored about the cultural influence on the adoption and use of e-government services $[10,11]$. Thus, culture makes remarkable influence on the acceptance and adoption of new technologies such as e-government services [14-16].

*Corresponding author: Ranaweera HMBP, School of Public Administration Huazhong University of Science and Technology, Wuhan, PR China, Tel: +94718344611; E-mail: buddiranaweera@yahoo.com

Received March 16, 2016; Accepted April 06, 2016; Published April 16, 2016

Citation: Ranaweera HMBP (2016) Role of National Culture on the Use of e-Government Services in Sri Lanka. J Bus Fin Aff 5: 182. doi:10.4172/21670234.1000182

Copyright: (C 2016 Ranaweera HMBP. This is an open-access article distributed under the terms of the Creative Commons Attribution License, which permits unrestricted use, distribution, and reproduction in any medium, provided the original author and source are credited. 
Culture is a complex concept and it cannot be defined easily. It is hard to find universally accepted definition for the term national culture [5]. Hofstede has done more research on culture and has identified the importance of culture for human behavior and their decisions. Simply, he has given a definition as a collective programming of the mind [19]. In other words, this implies that culture reflects the commonly accepted patterns of thinking and feelings of humans [20]. Thus, human's culture is shaped with the time, education, art and their own abilities. Culture distinguishes not only group of people (society or societies) but also organizations, industries, professions or even across countries [12]. With the time passing, people form agreements for certain things, share common things, build up norms and collect all those and demonstrate their history. By doing so, history itself represents the accumulated culture. People in a same culture act as same way and take decisions in similar manner for certain situations. Hence, behavior of human could be better understood by their representing culture, so that culture reflects and influence peoples' attitude, perception and their behavior $[21,22]$. Researchers have developed frameworks to understand and classify the world culture [23-25]. According to Hofstede's studies, culture can be identified with five dimensions namely power distance, individualism/collectivism, masculinity/feminine, uncertainty avoidance and long term orientation. With these dimensions he has compared world culture and has given scores for each dimension across countries [26].

Based on the scores of cultural dimensions, Sri Lanka is a multicultural country and characterized as a very collectivistic and masculine culture. In such a collectivism and masculine culture, word of mouth is very critical [27]. $75 \%$ of Sinhalese, $15.4 \%$ of Tamils, $9.2 \%$ of Moors and $0.4 \%$ of other ethnic groups are living in Sri Lanka. Buddhism - 70.2\%, Hindu - 12.7\%, Islam - 9.7\%, Roman Catholic - $6.1 \%$ and other religions $-1.3 \%$ are in Sri Lanka [28]. Hence, culture plays a significant role in Sri Lanka. In a collectivistic culture people are in a group and share their ideas and information each other for their safe. Loyalty is paramount and behaves as a family [24]. Power distance means the extent to which the members of a society accept that power is distributed unequally [24]. If the culture shows high power distance, it predicted to be less innovative [29]. Uncertainty avoidance means the degree to which societies can tolerate uncertainty and ambiguity. If the uncertainty avoidance is less, it says that tend to more innovative due to greater tolerance for risk [30]. Masculinity shows the gender role in society. Long-term orientation refers to people's consideration of the future [24]. Hofstede's cultural dimensions and theoretical framework have been accepted widely and have rewarded more recognition among scholars [5].

On the other hand, Hall [25] has presented two types of dimensions which represent the individual's culture. Individuals come under highcontext culture follows common ground to express knowledge and the same time expects others also follow same for the communication. These individuals expect and use implicit information. In contrast, individuals who come under low-context culture expect less common ground to communicate and tend to more verbose. Thus, according to Hall's two theories of high and low context, individuals comes from different culture are more favor to use their accustomed ways for sharing ideas. However his theory represents only how individuals do communications and it is different according to culture. Because his theory related to context and here context implies how communication is took place between two individuals. High context culture can be seen specially, in the countries of Middle East, Asia, Africa and South America while the countries belong to North America and much of Western Europe represent low context culture.
Both Hofstede and Hall's cultural dimensions have been criticized more individuals are living in a society and society represents a social unit of a country. Thus, a set of accepted norms, values and some kind of power structure can be seen and these are shaped by the culture. So that, it is reasonable to consider the cultural characteristics when implement new technological innovations like e-government. The most popular and extensively used cultural dimensions are the Hofstede's one [11] while Reay [31] asserts that cultural dimensions of Hofstede have used extensively in cross-cultural information technology studies. In addition, Reay [31] has pointed out the importance of culture in their study. They have considered Hofstede and Hall's cultural dimensions and examined how cultural characteristics of individuals impact for internet based websites. Finally they have concluded as technology adoption research should be carried out not only technological and legal perspectives but also socio-cultural perspectives.

Hofstede's five dimensions of culture are popular among researchers to evaluate culture. However, Yoo [27] argued that measures of Hofstede's five dimensions do not represent the culture at the individual level. So that Yoo [27] developed CVSCALE consisting 26 items to measure the culture with five dimensions of Hofstede. Adapa [32] did a study on "Adoption of Internet shopping: Cultural consideration in India and Australia". He has used CVSCALE to measure the culture with five dimensions of Hofstede. According to findings, he has concluded as culture makes influence for the adoption to technology. Accordingly, for the ongoing empirical study, CVSCALE is used to evaluate the culture with five dimensions of Power distance, Uncertainty avoidance, Collectivism, Long-Term orientation and Masculinity. National culture is considered as an external variable to TAM in this study. Based upon theories and literature intimated in the above sections, it is supposed to propose a relation concerning the influences of national culture on adoption and use of e-government services in Sri Lanka while assuming culture make some influence for perceived usefulness, perceived ease of use as well. Based on the above arguments following hypotheses are proposed aligning with TAM.

$\mathbf{H}_{\mathbf{1}}$ : National culture significantly influences the use of e-government services.

$\mathbf{H}_{2}$ : National culture significantly influences the perceived usefulness of e-government services.

$\mathbf{H}_{3}$ : National culture significantly influences the perceived ease of use of e-government services.

$\mathbf{H}_{4}$ : Perceived ease of use of e-government services significantly influences perceived usefulness.

$\mathbf{H}_{5}$ : Perceived usefulness of e-government services significantly influence attitudes towards to use of e-government services

$\mathbf{H}_{6}$ : Perceived ease of use of e-government services significantly influences attitudes towards to use of e-government services

$\mathbf{H}_{7}$ : Perceived usefulness of e-government services significantly influence the use of e-government services

$\mathbf{H}_{\mathbf{s}}$ : Attitudes towards use of e-government services significantly influence the use of e-government services.

\section{Theoretical Framework and the Research Model}

In term of user behavior towards to novel innovations; for instance e-government services, understanding the user behavior is much more important. Thus, behavioral adoption theories are vital and play a crucial role to get familiar and understand about the user behavior 
on adoption and use of e-government services. Accordingly, much more studies on the issues of e-government have been conducted with the support of technology adoption theories as the theoretical base. Thus, there can be identified numerous research models which have been acknowledged, modified and validated in the technology adoption research field [33]. Theory of Reasoned Action (TRA) by [34], Theory of Planed Behavior by [35], Diffusion of Innovation Theory by [36], and Technology Acceptance Model (TAM) found by [37] and Unified Theory of Acceptance and Use of Technology model from [33] are among the cited theories. Most of the researches have been acknowledged the TAM where the technology adoption and use is mandatory for employees in organizations, so that, TAM need to be applied and tested in different context where technology adoption and use is voluntary in particular e-government [5].

TAM is a significant model in the information technology research field [38]. In addition, they have ensured that selection of variable to TAM is determined according to a particular research domain or the type of research in hand. TAM model is formed by using different types of variables such as independent variables, dependent variables, control variables and external variables. However, it has been paid less attention on role of TAM external variables. External variables could have direct effect to the usage behavior [39]. Meanwhile, they posit that there are arguments on the importance of external variables to be studied since those would be ultimate driving forces of the usage of new technology innovations. One of TAM limitation is; TAM assumes that external variables make influence on usage only through the two constructs of perceived usefulness and perceived ease of use. However, there are arguments that external variables could have strong direct effect to the usage behavior [39].

The TAM provides avenue to explore how external variables influence internal variables of perceived usefulness, perceived ease of use, attitude, and intention to use. External variables may get varied according to diverse contexts [40]. Nevertheless, some key social factors like culture has not been concerned much more with TAM and pointed out the importance of culture [41]. Since the present research focuses on cultural influence towards adoption and use of e-government services and the TAM is flexible to add such social factors, theoretical background for the present study is supported by the well-established TAM which was derived from the TRA. According to TAM argument, people's attitudes towards to accept, adoption and use new technological innovations such as e-government is determined by perceived usefulness and perceived ease of use. Thus, the most important two constructs of TAM are perceived usefulness which has defined as "the degree to which a person believes that using a particular system would enhance his or her job performance" and perceived ease of use defined as "the degree to which a person believes that using a particular system would be free of effort" [37, p. 320]. Subsequently, considering the richness, solidity of the TAM model and flexibility for adding extra variables, TAM was extended with national culture. The extended TAM is depicted in the Figure 1.

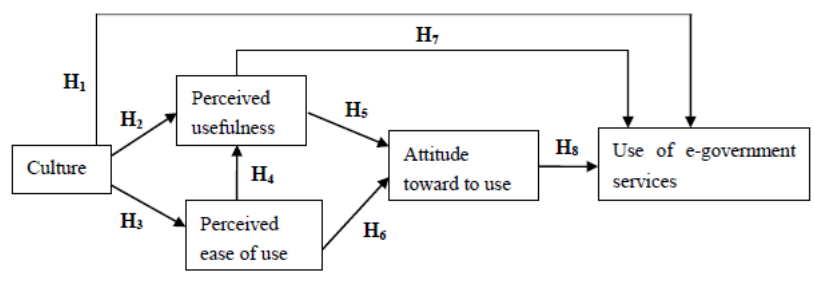

Figure 1: Research model

\section{Research Methodology and Analysis}

The two terms appeared in the research field are methodology and method. In research field, these two are used interchangeably [42]. However, these two cannot be separated when doing a research. The research problem, personal experience and people who take outcomes of the research are considered when selecting suitable approach to a research [43]. Considering all, deductive approach and survey strategy were used for the present study. Since, quantitative data is easy to make interpretations with statistical techniques [6]; structured questionnaire was administered to collect data numerically. The survey instrument was prepared concerning previous studies $[5,27,37,44,45]$ and modifications and changes were made to suite the research problem and the country context. The first section is devoted to catch the basic demographic attributes like age, gender, education etc. the experience of internet and government websites were asked in the section two. Section three and four cover the research variables of the study. The responses of the non-demographic items were recorded using five point likert scale ranging 1 for strongly disagree to 5 for strongly agree. A pilot study was held with 30 respondents before moving to the real collection of data. The purpose of pilot study was to understand any discrepancies of the survey items and make the clarifications. Feedback of the respondents who attend to survey suggested that instrument is easy to answer and length of the instrument was shortened accordingly. The analysis of the survey reveals that all inter correlations exceeds 0.30 for all survey items and value for total correlation exceeds 0.5 . Thus, questionnaire was finalized to continue the data collection.

The population of interest was e-government service users in Sri Lanka. Questionnaires were distributed among the six categories of users who come from five provinces. Table 1 shows the distribution of questionnaires by following multi stage procedure. Convenient sampling procedure was applied for the selection of respondents into sample. 1600 questionnaires were shared out and returned 1008. 898 were valid for the analysis showing 56\% responding rate. SPSS 16.0 was used for primary preparations and Amos 20.0 was selected for structural analysis (Table 1).

\section{Structural equation modeling}

Structural Equation Modeling (SEM) is popular among researchers and it has been increased the usage in many research areas; for example, psychology, sociology, education, political science and economic [4648]. The goal of the SEM approach is to test the structural relationships which hypothesized with existing theories and findings. Confirmatory Factor Analysis (CFA) is used to assess the goodness of fit of a model by comparing several statistical figures and indices. SEM can handle multiple variables simultaneously with more confidence and efficiently [49]. Basically, there are two approaches proposed by [48] to test a SEM model. First is the measurement model which shows the relationships between observed variables and latent variables. Measurement model is tested by using CFA. The second is the structural model which indicates paths between latent variables. The statistical figures and fit indices used to evaluate the model fit of measurement model are used to evaluate the structural model. These fit indices and figures are discussed in details in coming sections.

Quality of the outcomes in a research can be maintained by ensuring the internal consistency of the measurement items [50]. Thus, Cronbach's Alpha values were calculated and shown in Table 2. All the values are in the acceptable level with cut-off value 0.7 [51]. In addition, Average Variance Extracted (AVE), Construct Reliability (CR) as well as $\mathrm{KMO}$ values were observed to ensure the reliability and validity of 
Citation: Ranaweera HMBP (2016) Role of National Culture on the Use of e-Government Services in Sri Lanka. J Bus Fin Aff 5: 182. doi:10.4172/21670234.1000182

Page 4 of 7

\begin{tabular}{|l|c|c|c|c|c|c|}
\hline Province & Under graduates & Academics & Gov. Institutes & Private Organizations & Businessmen & Civilian \\
\hline Western & 200 & 40 & 60 & 60 & 20 \\
\hline Central & 100 & 40 & 60 & 60 & 20 \\
\hline North Western & 100 & 40 & 60 & 60 & 20 \\
\hline North Central & 100 & 40 & 60 & 60 & 20 \\
\hline Northern & 100 & 40 & 60 & 60 & 20 \\
\hline Total & 600 & 200 & 300 & 300 & 20 \\
\hline
\end{tabular}

Table 1: Research instrument distribution.

\begin{tabular}{|c|c|c|c|c|c|}
\hline Variable and constructs & No. of items & Cron. a & KMO Values & AVE & CR \\
\hline Use of e-government services (Useofe-Gov) & & & & 0.64 & 0.84 \\
\hline - $\quad$ Search information (SI) & 03 & 0.807 & 0.705 & & \\
\hline - $\quad$ Contact via government websites (CON) & 03 & 0.760 & 0.688 & & \\
\hline - Willingness to use government websites (WU) & 04 & 0.740 & 0.761 & & \\
\hline Attitude towards to use (A_use) & 08 & 0.875 & 0.903 & 0.59 & 0.92 \\
\hline Perceived usefulness (PU) & 09 & 0.863 & 0.895 & 0.52 & 0.91 \\
\hline Perceived ease of use (PEU) & 09 & 0.840 & 0.857 & 0.50 & 0.89 \\
\hline Culture & & & & 0.51 & 0.78 \\
\hline - $\quad$ Collectivism (COL) & 06 & 0.820 & 0.832 & & \\
\hline - $\quad$ Power distance (PD) & 05 & 0.814 & 0.815 & & \\
\hline - $\quad$ Long-term orientation (LTO) & 05 & 0.748 & 0.757 & & \\
\hline - Uncertainty avoidance (UA) & 03 & 0.764 & 0.686 & & \\
\hline - Masculinity (M) & 04 & 0.700 & 0.721 & & \\
\hline
\end{tabular}

Table 2: Calculated values for Cronbach's alpha, KMO, AVE and CR.

the constructs. All the values of AVE, CR and KMO exceed the cut-off values of 0.5 [52], 0.7 [49] and 0.5 [53] respectively (Table 2).

With ensuring the reliability and validity for all the constructs, it was formed the measurement model as depicted by Figure 2 and executed CFA. The results generated through the CFA were summarized in the Table 3.

Well fitted model shows the consistency between outcomes of a research and theory concerned. Various fit indices generated through CFA determine goodness of fit of a model and these fit indices have been suggested by previous studies [51,54]. There are three types of evaluations for a model fit in SEM analysis called as absolute fit, incremental fit and parsimonious fit. Normalized Chi-square, Root Mean Square Error of Approximation (RMSEA) and Goodness of Fit Index (GFI) come under absolute fit indices and considered as most significant fit indices which indicate goodness of fit for a model [51]. Adjusted Goodness of Fit Index (AGFI), Comparative Fit Index (CFI), Normed Fit Index (NFI) and Trucker Lewis Index (TLI) are considered as incremental fit indices while Normalized Chi-square treated as parsimonious fit index (Figure 2).

The results of the CFA reveal that value for the normed chisquare of the model is good and value falls in the acceptable range of 5. Normally, the value below 5 is considered as good [51]. Other fit indices of GFI, AGFI, CFI, NFI and TLI also show better fit for the model. The values for these indices range from 0 to 1 and value closer to 1 indicates good fit. Value for the RMSEA is 0.043 and this is less than cut-off value 0.08 . If value for this index is less than 0.06 , then it is said that model is better fit. In addition, RMR index also shows a good value having 0.032 . In term of RMR, value less than 0.08 shows good fit. Accordingly, considering all the fit indices the measurement model was validated and accepted for further analysis in the next step.

Having confirmed the measurement model, the path diagram was developed as illustrated in Figure 3. The structural model supports to assess the hypothesized paths in the path diagram. Thus, developed

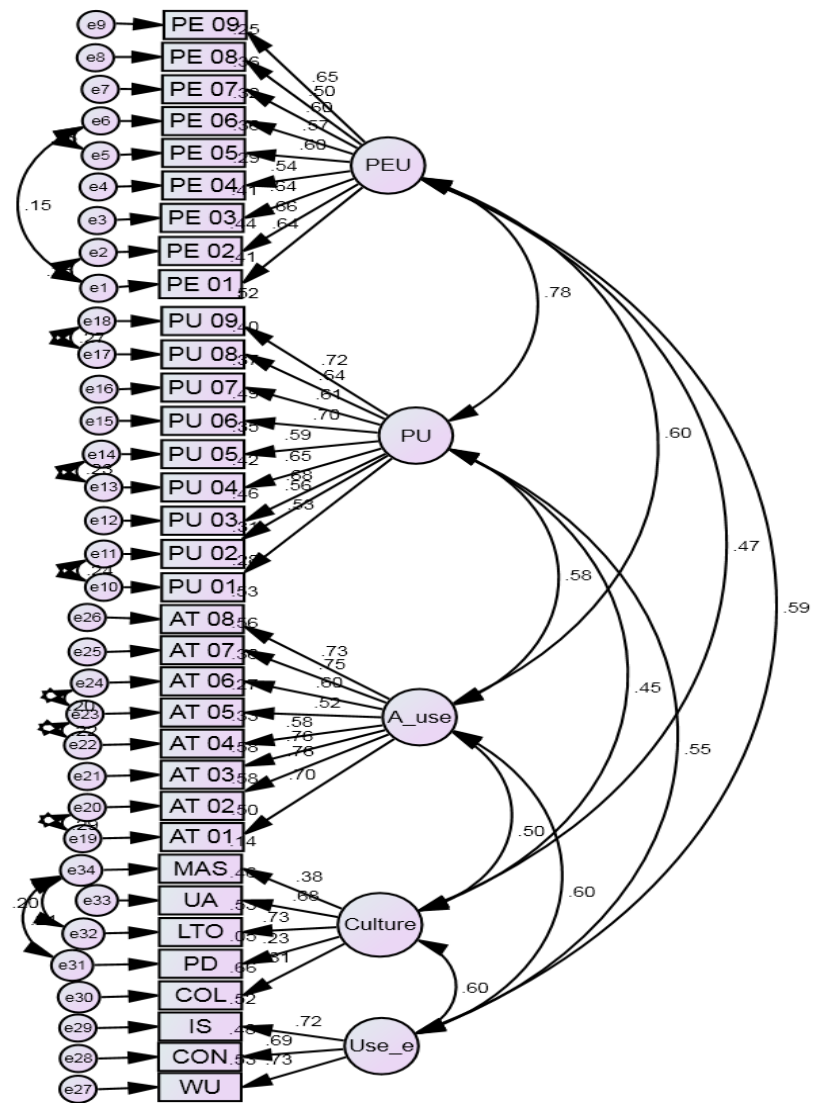

Figure 2: Measurement model.

hypotheses can be tested with the results of structural analysis. Same as to CFA in measurement model, fit indices are produced after executing structural analysis. Table 4 summarized the results (Figure 3). 
Citation: Ranaweera HMBP (2016) Role of National Culture on the Use of e-Government Services in Sri Lanka. J Bus Fin Aff 5: 182. doi:10.4172/21670234.1000182

Page 5 of 7

\begin{tabular}{|l|c|c|c|c|c|c|c|c|c|}
\hline & Chi-square & GFI & AGFI & CFI & NFI & TLI & RMSEA & RMR & p-value \\
\hline Measurement model & 2.637 & 0.908 & 0.892 & 0.931 & 0.893 & 0.923 & 0.043 & 0.032 & 0.000 \\
\hline
\end{tabular}

Table 3: Values for fit indices of CFA (Measurement Model).

\begin{tabular}{|l|c|c|c|c|c|c|c|c|c|c|}
\hline & Chi-square & GFI & AGFI & CFI & NFI & TLI & RMSEA & RMR & p-value \\
\hline Structural model & 2.769 & 0.901 & 0.884 & 0.925 & 0.887 & 0.917 & 0.044 & 0.034 & 0.000 \\
\hline
\end{tabular}

Table 4: Values for fit indices of Structural model.

\begin{tabular}{|c|c|c|c|c|}
\hline \multicolumn{3}{|l|}{ Direct paths (Hypotheses) } & \multirow{2}{*}{$\frac{\mathbf{P}}{\star \star \star \star}$} & \multirow{2}{*}{$\begin{array}{l}\text { SRW } \\
0.363\end{array}$} \\
\hline Culture & $\rightarrow$ & Use of e-gov. service (Use_e) $H_{1}$ & & \\
\hline Culture & $\rightarrow$ & Perceived usefulness (PU) $\mathbf{H}_{2}$ & 0.026 & 0.086 \\
\hline Culture & $\rightarrow$ & Perceived ease of use (PEU) $\mathbf{H}_{3}$ & $* * *$ & 0.503 \\
\hline Perceived ease of use (PEU) & $\rightarrow$ & Perceived usefulness (PU) $\mathbf{H}_{4}$ & *** & 0.738 \\
\hline Perceived usefulness (PU) & $\rightarrow$ & Attitudes toward to use (A_use) $\mathbf{H}_{5}$ & $* * *$ & 0.257 \\
\hline Perceived ease of use (PEU) & $\rightarrow$ & Attitudes toward to use (A_use) $\mathbf{H}_{6}$ & $* \star *$ & 0.422 \\
\hline Perceived usefulness (PU) & $\rightarrow$ & Use of e-gov. service (Use_e) $\mathbf{H}_{7}$ & $* * *$ & 0.233 \\
\hline Attitudes towards to use (A_use) & $\rightarrow$ & Use of e-gov. service (Use_e) $\mathbf{H}_{8}$ & $* * *$ & 0.304 \\
\hline
\end{tabular}

*** represent $\mathrm{p}<0.001$

Table 5: Standardized regression weights of the paths.

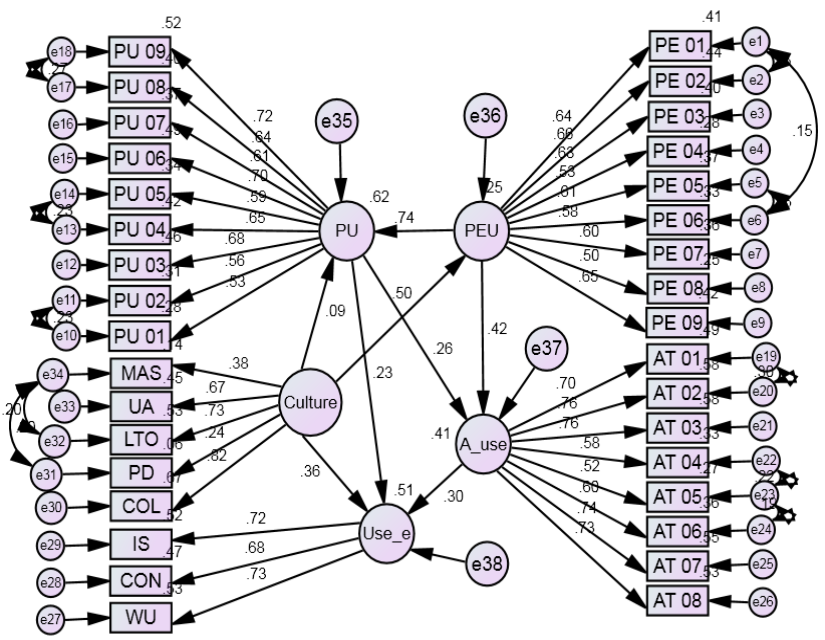

Figure 3: Structural model

The Table 4 gives the figures of fit indices of the structural analysis. Figures say that model is significant with $\mathrm{p}<0.000$. The Normed Chisquare value of 2.769 is less than the threshold value of 5 . In general, the value of Normed Chi-square is more attracted from researchers for the purpose of identification and assessing the model fit. However, [51] suggested and argued that a model can be accepted if there is at least one absolute fit index and one incremental fit index are matched with generally accepted cut-off values. In term of incremental fit indices, the most widely used fit index is CFI and considers it as a key index to determine the goodness of fit for a model. The reported values for RMSEA and RMR are 0.044 and 0.034 respectively and the values are less than the 0.8 which is the accepted cut-offs. Value of CFI is 0.925 and figure exceeds the cut-off value of 0.9 . Hence, two absolute fit indices and one incremental fit index are accepted with cut-offs for the present study. Accordingly, it gives evidence of the goodness of fit for the proposed model. Moreover, other incremental fit indices of AGFI, NFI, and TLI are very much closer to cut-offs and give evidences for the goodness of fit of the model (Table 4).

\section{Results and Discussion}

The results of the structural model indicate that all structural paths of the path diagram were statistically significant while showing positive relations between concerned factors and the Standardized Regression Weights (SRW) are compiled in the Table 5. Accordingly, developed all eight hypotheses were supported and accepted (Table 5).

The first hypothesis $\left(\mathbf{H}_{\mathbf{1}}\right)$ was built between national culture and use of e-government services. The reported regression weight is 0.363 and this implies that use of e-government services is explained by $36.3 \%$ of national culture. $[4,55,56]$ noted national culture make influence on adoption behavior. [14], based on their results have shown that access and skills to use e-government services may vary by culture. Evans and Yen [15] also have confirmed that individual's culture plays a significant role for adoption and use of e-government services. Kim [21] findings also are similar to above scholar's findings. Thus, findings mentioned in the above are consistent with findings of this study. It implies that culture makes influence on people's behavior to use e-government services. However, Lean [57] has found through their study and posited as culture does not make influences on use of e-government services. So that, finding of this study are not congruent with [57].

Yoo [27] CVSCALE was used to operationalize the cultural factor, [26] five cultural dimensions which are power distance, collectivism, masculinity, uncertainty avoidance and long term orientation. In the Sri Lankan context, the results of the structural analysis disclose that the most contributing dimension to culture is collectivism (SRW 0.816). The next importance is gone to long term orientation (SRW - 0.727). Uncertainty avoidance (SRW - 0.677) is the third significant dimension of the national culture. Masculinity and power distance are the less contributing dimensions to culture; nonetheless, their relationships were significant. Thus, collectivism, long term orientation and uncertainty avoidance make a significant influence for the national culture in Sri Lanka. Al-Hujran [5] pointed out that power distance and uncertainty avoidance have positive influences on the adoption and use of e-government services. Furthermore other three dimensions have not considered due to less significant. Warkentin [58] findings also are consistent with above the findings. Zhang [17] come up with findings with two cultural dimensions of power distance and individualism and pointed out these two make significant influence for adoption and use of new technologies. Accordingly, findings of this study are little bit 
deviate with Al-Hujran [5] and Warkentin [58] meanwhile findings of Zhang [17] are not matched with present study.

The results confirm that people in Sri Lankan culture take decisions collectively, when they take decisions; individuals always concern about others and examine what others do. Afterwards collect information and based on that make decisions. At the same time, people think more about the past and future when take decisions. They do not like short term arrangements. They prefer to have more benefits paying attention on past and future. Another interesting point is; people always try to avoid from the threat of uncertainty situations and do not take much more risk on their decision making process. Thus, people in high uncertainty culture are not interested to take challenges. Accordingly, if people feel that e-government websites have uncertainty or risk situations and do not provide more benefits or desired outcomes, by concerning past and future, they will avoid using them. People take collective decisions to adopt and use or not e-government services though government invest huge money for implementing e-government projects. Thus, in term of national culture in Sri Lanka, it reflects collectivism, long term orientation and uncertainty avoidance are as key dimensions which contribute to determine the people's behavior towards the use of e-government services in Sri Lanka.

As intimated in the section two, national culture was treated as an external variable to the TAM. Hence, the formulated hypothesis number two $\left(\mathrm{H}_{2}\right)$ which represents a relationship from culture to perceived usefulness of e-government websites was supported. However, the reported influence is less since a smaller amount of weight (0.086). However, hypothesis number three $\left(\mathrm{H}_{3}\right)$ which represents a relationship with culture and perceived ease of use of e-government websites is strongly supported. The influence of national culture on ease of use is considerably high. The reported percentage is 50.3. Consequently, especially three dimensions of national culture make influence significantly on perceived ease of use of e-government services in Sri Lanka. This finding shows positive insights of the users towards the technology adoption with easiness for use due to national cultural influences. The rest hypotheses $\left(\mathrm{H}_{4}, \mathrm{H}_{5}, \mathrm{H}_{6}, \mathrm{H}_{7}\right.$ and $\left.\mathrm{H}_{8}\right)$ also are supported and accepted. Once again this outcome strongly ensures the prediction power of the TAM confirming the suitability in the Sri Lankan context. Furthermore, according to the statistical evidence the $\mathrm{R}^{2}$ for use of e-government services is 0.511 , thus it reveals as the used model is explained the $51.10 \%$ of the use of e-government services in Sri Lanka.

\section{Conclusion}

The study conducted was focused to identify the influence of national culture on the use of e-government services in Sri Lanka. The SEM approach was applied for the analysis and produced results of the structural assessment strongly suggest that national culture of the country makes influences on the use of e-government services. Furthermore, results exposed that Hofstede's cultural dimensions of collectivism, long term orientation and uncertainty avoidance are significant in Sri Lankan context and make strong contribution to national culture. In addition, national cultural traits have positive significant relations with the key constructs of perceived ease of use and perceived usefulness in TAM. These findings give strong evidences about the behavior patterns of Sri Lankans towards the adoption and use of e-government services. Peoples' thinking about the ease of use of e-government services are highly influenced by their culture and with that ease of use makes influence towards the usefulness of the e-government services. As a whole, extended TAM with national culture was validated in Sri Lankan context and use of e-government services is explained by $51.10 \%$. E-government initiatives should be customized based on country own culture. Thus, these research findings will open policy makers eyes towards the national culture and it's traits to be concerned when invest, develop and implement e-government projects in future meanwhile outcomes will be benefited for the stakeholders in the field of e-government and it can be applied in similar contexts.

\section{Limitations and Future Directions}

This study was limited for only five provinces in the country and six categories of e-government service users. TAM was considered as the theoretical background and model is extended by adding only national culture as an external variable. Accordingly, it is worth to consider more areas of the country representing more different categories of user to be drawn the conclusions and the generalization of the results concerning the entire country. The unexplained $48.90 \%$ of the model may be due to other influencing factors like trustworthiness, awareness, physical facilities of ICT as well as other type of external variables such as organizational and environmental attributes etc. thus these limitations can be addressed in future studies.

\section{References}

1. Alomari MK (2014) Discovering citizens reaction toward r-government: Factors in e-government adoption. Journal of Information System and Technology Management 11: 5-20.

2. Boland KM, McNutt JG (2013) Assessing E-Government Success Strategies using Internet Search Data. In J. Gil-Garcia (Ed), E-Government Success Factors and Measures: Theories, Concepts, and Methodologies. CIDE, Mexico pp: 289-307.

3. Ali M, Weerakkody V, El-Haddadeh R (2009) The Impact of National Culture on eGovernment implementation: A Comparison Case Study. Proceedings of the Fifteenth Americas Conference on Information Systems, San Francisco, California pp: $1-13$

4. Akkaya C, Wolf $P$, Kremar H (2012) Factors Influencing Citizen Adoption of E-Government Services: A cross-cultural comparison (Research in progress). 45th Hawaii International Conference on System Sciences pp: 2531-2540.

5. Al-Hujran O, Al-dalahmeh M, Aloudat A (2011) The role of National Culture on Citizen Adoption of eGovernment Services: An Empirical Study. Electronic Journal of e-Government 9: 93-106.

6. Shajari M, Ismail Z (2013) Testing an Adoption Model for E-Government Services Using Structural Equation Modeling. International Conference on Informatics and Creative Multimedia pp: 298-303.

7. Prima S, Ibrahim R (2011) Citizen Awareness to e-government services fo information personalization. International Journal of Innovative computing 1 : $1-14$.

8. Rana NP, Dwivedi YK, Williams MD (2015) A meta-analysis of existing research on citizen adoption of e-government. Information Systems Frontiers 17: $547-563$

9. Alsaif M (2014) Factors Affecting Citizens' Adoption of e-Government Moderated by Socio-Cultural Values in Saudi Arabia. Proceedings of the European Conference on e-Government pp: 578.

10. Nurdin N, Stockdale R, Scheepers H (2010) Examining the role of the Culture of Local Government on Adoption and Use of E-Government Services. E-government, E-services and Global Processes 334: 79-93.

11. Sabri A, Sabri O, Al-Shargabi B (2012) A Cultural E-Government Readiness Model. Intelligent Information Management 4: 212-216.

12. Martinsons MG, Davison RM, Martinsons V (2009) How Culture Influences ITEnabled Organizational Change and Information Systems. Communications of the ACM 52: 118-123.

13. Victor B, Moody R (2004) Visual Culture and Electronic Government: Exploring a New Generation of E- Government. Proceedings of EGOV, Zaragoza pp: 257-269. 
14. Carter L, Weerakkody V (2008) E-government adoption: A cultural comparison. Information system Frontier 10: 473-482.

15. Evans D, Yen DC (2006) E-Government: Evolving relationship of citizens and government, domestic and international development. Government Information Quarterly 23: 207-235.

16. AlAwadhi S, Morris A (2009) Factors Influencing the Adoption of E-government services. Journal of Software 4: 584-590.

17. Zhang N, Guo X, Chen G (2011) Why adoption and use behavior of IT/IS cannot last? - two studies in China. Information System Frontiers 13: 381-395.

18. AlShihi H (2005) E-government Development and Adoption Dilemma: Oman Case Study. In Proceedings of the 6th International We-B (Working for eBusiness) Conference. Victoria University, Melbourne, Australia.

19. Hofstede G (1980) Culture's Consequences: International Differences in WorkRelated Values. Beverly Hills, Sage, CA.

20. Hofstede G (1991) Cultures and Organizations: Software of the Mind. McGrawHill, London, UK.

21. Kim J-H (2013) Information and culture: Cultural differences in the perception and recall of information. Library and Information science Research 35: 241 250.

22. Rettie R (2002) Net generation culture. Journal of Electronic Commerce Research 3: 254-264

23. Hofstede G (1997) Cultures and Organizations: Software of the Mind. McGrawHill, New York.

24. Hefstede G, Hofstede GJ, Minkov M (2010) Cultures and Organizations, Software of the Mind: Intercultural Cooperation and Its Importance for Survival. (3rdedn), McGraw-Hill publishers.

25. Hall ET (1989) Beyond Culture. Doubleday, New York.

26. Hofstede G (2003) Geert Hofstede cultural dimensions.

27. Yoo B, Donthu N, Lenartowicz T (2011) Measuring Hofstede's Five Dimensions of Cultural Values at the Individual Level: Development and Validation of CVSCALE. Journal of International Consumer Marketing, 23: 193-210.

28. Department of Census and Statistics (2012) Census and Statistic Survey Report. Sri Lanka.

29. Herbig PA, Miller JC (1991) The Effect of Culture upon Innovativeness: A Comparison of United States and Japan Sourcing Capabilities. Journal of International Consumer Marketing 3: 7-53.

30. Yeniyurt S, Townsend JD (2003) Does Culture Explain Acceptance of New Products in a Country? An Empirical Investigation. International Marketing Review 20: 377-396

31. Reay I, Beatty P, Dick S, Miller J (2013) Privacy policies and national culture on the internet. Information Systems Frontiers 15: 279-292.

32. Adapa S (2008) Adoption of Internet Shopping: Cultural Considerations in India and Australia. Journal of Internet Banking and Commerce 13: 1-17.

33. Venkatesh V, Morris M, Davis G, Davis F (2003) User acceptance of information technology: Toward a unified view. MIS Quarterly 27: 425-478.

34. Douglass RB, Fishbein M, Ajzen I (1977) Belief, Attitude, Intention and Behavior: An Introduction to Theory and Research. Addison-Wesley, Reading, MA 10: $130-132$

35. Ajzen I (1991) The Theory of Planned Behavior. Organizational Behavior and Human Decision Processes 50: 179-211.

36. Rogers EM (2010) Diffusion of Innovation. Free Press, New York, NY.

37. Davis FD (1989) Perceived Usefulness, Perceived Ease of Use, and User Acceptance of Information Technology. MIS Quarterly 13: 319-340.

38. Yuanquan L, Jiayin Q, Huaying S (2008) Review of Relationships among Variables in TAM. Tsinghua Science and Technology 13: 273-278.

39. Burton-Jones A, Hubona GS (2006) The mediation of external variables in the technology acceptance model. Information \& Management 43: 706-717.

40. Sadeghi T, Farokhian S (2010) Electronic Banking Acceptance Model (EBAM) in Iran. World Applied Science Journal 11: 513-525.

41. Abbasi MS, Tarhini A, Hassouna M, Shah F (2015) Social, Organizational,
Demography and Individuals' Technology Acceptance Behaviour: A Conceptual Model. European Scientific Journal 11: 48-76.

42. Saunders M, Lewis P, Thornhill A (2009) Research methods for business students. (5thedn) Pearson Education, FT Prentice Hall publishers.

43. Creswell JW (2003) Research design: Qualitative, quantitative and mixed methods approaches. (2ndedn) Sage Publication Inc, California.

44. Shareef MA, Kumar V, Kumar U, Dwivedi YK (2011) e-Government Adoption Model (GAM): Differing service maturity level. Government Information Quarterly 28: 17-35.

45. AlAwadhi S, Morris A (2008) The use of the UTAUT Model in the Adoption of E-government Services in Kuwait. Proceeding of the 41st Hawaii International Conference on System Science pp: 219.

46. Khine MS (2013) Application of Structural Equation Modeling in Educationa Research and Practice. Sense publishers pp: 3-21.

47. Lei PW, Wu Q (2007) An NCME Instructional Module on Introduction to Structural Equation Modeling: Issues and Practical Considerations. Educational Measurement: Issues and Practice 26: 33-43.

48. Anderson JC, Gerbing DW (1988) Structural Equation Modeling in Practice: A Review and Recommended Two-Step Approach. Psychological Bulletin 103 411-423.

49. Byrne BM (2010) Structural Equation Modeling with AMOS. Basic Concepts, Applications and Programming. (2ndedn) Routledge, New York/London.

50. Sekaran U (2003) Research Methods for Business - A Skill Building Approach. John Wiley \& Sons, India.

51. Hair J, Black W, Babin B, Anderson R, Tatham R (2006) Multivariate Data Analysis. (6thedn) Pearson Educational International-Prentice Hall, Upper Saddle River, New Jersey.

52. Rosebush M (2011) Validations of the Character Mosaic Report. Technical Report, 1-65.

53. Field AP (2005) Discovering statistical using SPSS. (2ndedn) Sage, London

54. Hu L, Bentler PM (1999) Cutoff criteria for fit indexes in covariance structure analysis: Conventional criteria versus new alternatives. Structural Equation Modeling 6: 1-55.

55. Srite M, Karahanna E (2006) The role of espoused national cultural values in technology acceptance. MIS Quarterly 30: 679-704.

56. Patel H, Jacobson D (2008) Factors Influencing Citizen Adoption of E-Government: A Review and Critical Assessment. European Conference on Information Systems (ECIS) 2008 Proceedings.

57. Lean OK, Zailani S, Ramayah T, Fernando Y (2009) Factors influencing intention to use e-government services among citizens in Malaysia. International Journal of Information Management 29: 458-475.

58. Warkentin M, Gefen D, Pavlou PA, Rose GM (2002) Encouraging Citizen Adoption of e-Government by Building Trust. Routledge Taylor and French Group 12(3): 157-162.

\section{Acknowledgement}

I am bound to convey my heartfelt gratitude and deep thankfulness to my Supervisor, Professor Yi Zhang, School of Public Administration, Huazhong University of Science and Technology, Wuhan, PR China. He is a wonderfu character and teacher for me and he gave valuable guidance and comments to get better quality of the paper. In addition I would like to give my thanks those who review the paper and their comments were worth to enhance the level of the paper 